\title{
Monodisperse Formamidinium Lead Bromide Nanocrystals with Bright and Stable Green Photoluminescence
}

\author{
Loredana Protesescu, ${ }^{\dagger \dagger}$ Sergii Yakunin, ${ }^{\dagger, \ddagger}$ Maryna I. Bodnarchuk, ${ }^{\dagger, \ddagger}$ Federica Bertolotti, ${ }^{\S}$ \\ Norberto Masciocchi, ${ }^{\S}$ Antonietta Guagliardi, ${ }^{\S, \perp}$ and Maksym V. Kovalenko*, ${ }^{*,+}$ \\ ${ }^{\dagger}$ Institute of Inorganic Chemistry, Department of Chemistry and Applied Bioscience, ETH Zürich, Vladimir Prelog Weg 1, CH-8093 \\ Zürich, Switzerland \\ ${ }^{\ddagger}$ Laboratory for Thin Films and Photovoltaics, Empa - Swiss Federal Laboratories for Materials Science and Technology, \\ Überlandstrasse 129, CH-8600 Dübendorf, Switzerland \\ ${ }^{\S}$ Dipartimento di Scienza e Alta Tecnologia and To.Sca.Lab, Università dell’Insubria, via Valleggio 11, I-22100 Como, Italy \\ ${ }^{\perp}$ Istituto di Crystallografia and To.Sca.Lab, Consiglio Nazionale delle Ricerche, Valleggio 11, I-22100 Como, Italy
}

Supporting Information

ABSTRACT: Bright green emitters with adjustable photoluminescence (PL) maxima in the range of 530$535 \mathrm{~nm}$ and full-width at half-maxima (fwhm) of $<25 \mathrm{~nm}$ are particularly desirable for applications in television displays and related technologies. Toward this goal, we have developed a facile synthesis of highly monodisperse, cubic-shaped formamidinium lead bromide nanocrystals $\left(\mathrm{FAPbBr}_{3} \mathrm{NCs}\right)$ with perovskite crystal structure, tunable $\mathrm{PL}$ in the range of $470-540 \mathrm{~nm}$ by adjusting the nanocrystal size (5-12 nm), high quantum yield (QY) of up to $85 \%$ and PL fwhm of $<22 \mathrm{~nm}$. High QYs are also retained in films of $\mathrm{FAPbBr}_{3} \mathrm{NCs}$. In addition, these films exhibit low thresholds of $14 \pm 2 \mu \mathrm{J} \mathrm{cm}^{-2}$ for amplified spontaneous emission.

T $\mathrm{n}$ the last several years, lead halide semiconductors with 1 perovskite crystal structures have emerged as very popular optoelectronic materials, initially in the context of highly efficient photovoltaics with power conversion efficiencies exceeding $22 \%^{1}$ and as versatile photonic sources. In particular, nanocrystals (NCs) of colloidal cesium lead halides $(\mathrm{CsPbX}, \mathrm{X}$ $=\mathrm{Cl}, \mathrm{Br}$, or $\mathrm{I}$, or a mixture thereof) have been recently shown to possess outstanding optical properties such as broadly tunable photoluminescence (PL) $(410-700 \mathrm{~nm})$, small fullwidth at half-maxima ( $\mathrm{fwhm}=12-40 \mathrm{~nm}$ for blue to red) and high PL quantum yields (QYs $=50-90 \%) .^{2}$ At present, these materials are undergoing further chemical engineering ${ }^{3}$ and are intensely investigated in several respects, e.g., as to their surface chemistry, ${ }^{4}$ lasing characteristics ${ }^{5}$ and service in light-emitting devices. ${ }^{4 b, 6}$ In the near future, the technologically most feasible application of these NCs is in television displays and related devices, where perovskite NCs might act as green and red emitters excited by standard blue-emitting diodes. Bright-green $\mathrm{PL}$ with adjustable maxima in the range of $530-535 \mathrm{~nm}$, a facile reproducibility of $\pm 1 \%$ or better, and fwhm of $<25 \mathrm{~nm}$ is a particularly desirable milestone, considering NTSC and more recent Rec.2020 color standards. Our studies on $\mathrm{CsPbX}_{3} \mathrm{NCs}$ have demonstrated the difficulties in achieving and maintaining such desirable " $530-535 \mathrm{~nm}$ " PL in a solid, polymer-embedded state. First of all, both the PL peak and absorption edge from $\mathrm{CsPbBr} \mathrm{Pb}_{3} \mathrm{NCs}$ do not exceed $520 \mathrm{~nm}$, even at NC sizes far beyond the quantum-confinement regime $(>10 \mathrm{~nm})$. This is indicative of the fact that the "apparent bulk bandgap" of $\mathrm{CsPBr}_{3} \mathrm{NCs}$ is higher than that obtained with large single crystals (with a band gap of $2.25 \mathrm{eV}$ at, e.g., $551 \mathrm{~nm}$ ). ${ }^{7}$ At present, the atomistic origin of this difference is unclear. The broad X-ray diffraction (XRD) reflections of $\mathrm{CsPbBr}_{3} \mathrm{NCs}$ make it difficult to differentiate between the orthorhombic (nearly cubic) lattice of the bulk material and other possible distortions of the ideal cubic lattice. The PL maxima can be pushed to the desired 530-535 $\mathrm{nm}$ wavelengths compositionally, by forming $\mathrm{CsPbBr}_{3-x} \mathrm{I}_{x}(x \approx 0.3)$. However, this shift is accompanied by a drop of QY from 90 to $\leq 50 \%$. Furthermore, $\mathrm{CsPbr}_{3-x} \mathrm{I}_{x}$ NCs exhibit low chemical stability in the solidstate, presumably due to phase-separation into $\mathrm{CsPbBr}_{3}$ and $\mathrm{CsPb}_{3}$. Considerable attention has also been devoted to hybrid perovskites, methylammonium lead halides $\left(\mathrm{MAPbX}_{3}\right)$, in the form of colloidal NCs. ${ }^{8}$ A particular challenge facing MA-based compounds is their chemical decomposition, releasing gaseous methylamine.

In this work, we explored a closely related compound $\mathrm{FAPbBr}_{3}$, where $\mathrm{FA}^{+}$stands for $\mathrm{CH}\left(\mathrm{NH}_{2}\right)_{2}^{+}$(formamidinium). We present a colloidal synthesis of $\mathrm{FAPbBr}_{3} \mathrm{NCs}$ and strong evidence that these NCs may overcome the difficulties facing $\mathrm{Cs} \mathrm{PbBr}_{3} \mathrm{NCs}$ in achieving bright and stable emission at 530$535 \mathrm{~nm}$. In a typical hot-injection synthesis (method 1 , see Supporting Information for further details), FA-Pb precursor solution was prepared by reacting $\mathrm{Pb}$ and $\mathrm{FA}$ acetates $(0.2$ and $0.75 \mathrm{mmol}$, respectively) with oleic acid (OA, $2 \mathrm{~mL}$ ) in octadecene (ODE, $8 \mathrm{~mL}$ ). At $130^{\circ} \mathrm{C}$, oleylammonium bromide (OAmBr, $0.6 \mathrm{mmol}$, dissolved in $2 \mathrm{~mL}$ of toluene) was injected. After $10 \mathrm{~s}$, the $\mathrm{FAPbBr}_{3} \mathrm{NCs}$ were cooled to room temperature and purified using toluene and acetonitrile as a solvent and nonsolvent, respectively. This simple synthesis yields brightly luminescent, cubic-shaped and highly monodisperse $\mathrm{FAPbBr}_{3}$ NCs (Figure 1), with standard size deviation below 5\% (Figure $\mathrm{S} 1)$.

Received: August 24, 2016

Published: October 13, 2016 

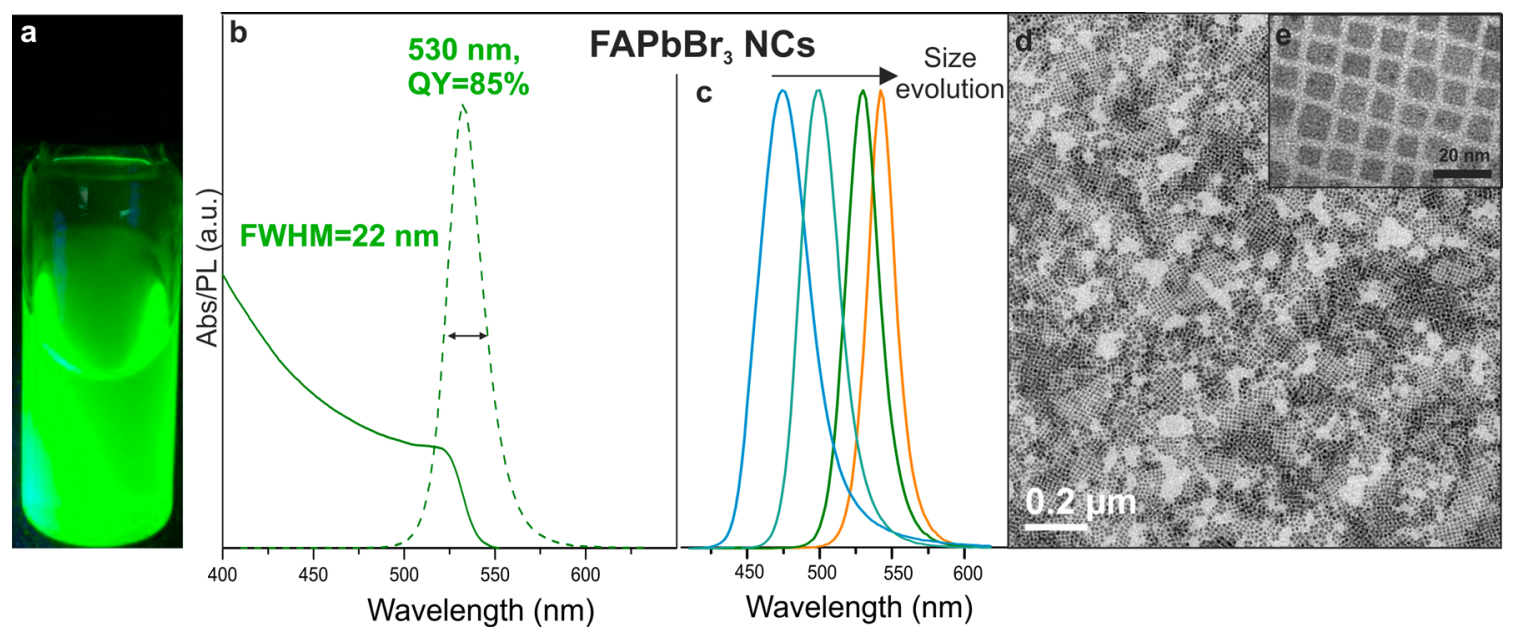

Figure 1. (a) Photograph of colloidal $\mathrm{FAPbBr}_{3}$ NCs in toluene solution under a UV lamp $(\lambda=365 \mathrm{~nm})$, (b) absorption and PL spectra of $\sim 12 \mathrm{~nm}$ $\mathrm{FAPbBr}_{3} \mathrm{NCs}$ with a PL maximum at $530 \mathrm{~nm}$, fwhm of $22 \mathrm{~nm}$ and QY of $85 \%$, (c) PL spectra for $\mathrm{FAPbBr}_{3}$ NCs showing the red shift of the emission peak with increasing size from 5 to $>50 \mathrm{~nm}$, (d,e) TEM images of $\sim 12 \mathrm{~nm} \mathrm{FAPbBr} 3$ NCs.

The excellent PL properties of $\mathrm{FAPbBr}_{3} \mathrm{NCs}$ are exemplified by those of $12 \mathrm{~nm}$ in size, which exhibit a PL maximum at 530 $\mathrm{nm}, \mathrm{QY}$ of $85 \%$ and fwhm of $22 \mathrm{~nm}$ (Figure $1 \mathrm{~b}$ ). The PL can be tuned in a wide range from 470 to $535 \mathrm{~nm}$ via size effects alone, without altering the composition. With $\mathrm{NC}$ sizes of up to $50 \mathrm{~nm}$ (Figure S2), PL peak values of up to $550 \mathrm{~nm}$ can be achieved, similar to the range reported for thin-film and bulk $\mathrm{FAPbBr}_{3}(550-575 \mathrm{~nm})$. $^{9}$ Size-engineering was accomplished by adjusting either the amount of $\mathrm{OAmBr}$ injected (a higher quantity leads to smaller NCs, Figure S3) or the reaction temperature (between 70 and $165{ }^{\circ} \mathrm{C}$, higher yielding larger size). We note that this synthesis (method 1 ) is significantly different from our previous work on $\mathrm{CsPbBr}_{3} \mathrm{NCs}$, where $\mathrm{PbBr}_{2}$ (dissolved in oleylamine, OLA, and $\mathrm{OA}$ ) was used as a $\mathrm{Pb}-\mathrm{Br}$ dual-source precursor. ${ }^{2}$ Such a $\mathrm{CsPbr}_{3}$-like synthesis of $\mathrm{FAPbBr}_{3} \mathrm{NCs}$ (method 2, see Supporting Information for details), which is by injection of FA-oleate precursor into $\mathrm{PbBr}_{2}$ /oleylamine/oleic acid mixture, yields a much broader size distribution of the NCs (Figure S4) than method 1. We attribute this to the detrimental role of molecular OLA, presumably causing deprotonation of $\mathrm{FA}^{+}$. Likewise, no $\mathrm{FAPbBr}_{3} \mathrm{NCs}$ could be obtained also when neutral OLA is introduced into method 1. An alternative Br-precursor, $\mathrm{CH}_{3} \mathrm{MgBr}$, has also been tested (method 3, see Supporting Information for details), leading to even faster reaction kinetics and thus poorer control over the NC size (Figure S5) than with $\mathrm{OAmBr}$ precursor. The complete absence of OLA or $\mathrm{OAm}^{+}$led to lower colloidal stability, reinforcing the OAmBr-based method 1 as, thus far, the optimal synthesis route. Besides acting as the $\mathrm{Br}$ source, $\mathrm{OAmBr}$ also brings the $\mathrm{OAm}^{+}$cation that together with the oleate-anion acts as capping ligands at the NC surfaces, presumably similarly to the $\mathrm{CsPBr}_{3}$ system. ${ }^{4 a}$ Oleylammonium oleate is the sole byproduct of the synthesis (method 1) and a capping ligand at the same time, with oleate coordinating surface cations and $\mathrm{OAm}^{+}$binding to surface anions. It is essential that the $\mathrm{FA}: \mathrm{Pb}$ molar ratio is maintained above 2 in order to obtain stable luminescence materials. For $\mathrm{FA}: \mathrm{Pb}$ ratios lower than 2, the obtained $\mathrm{NCs}$ rapidly decomposed. In contrast, $\mathrm{CsPbBr}$. NCs require a high excess of $\mathrm{Pb}$ for optimal growth. ${ }^{2,3 \mathrm{~g}}$

$\mathrm{XRD}$ studies on $\mathrm{FAPbBr}_{3} \mathrm{NCs}$ in thin films (Figure S6, laboratory data) and in solutions (Figure 2, synchrotron data)

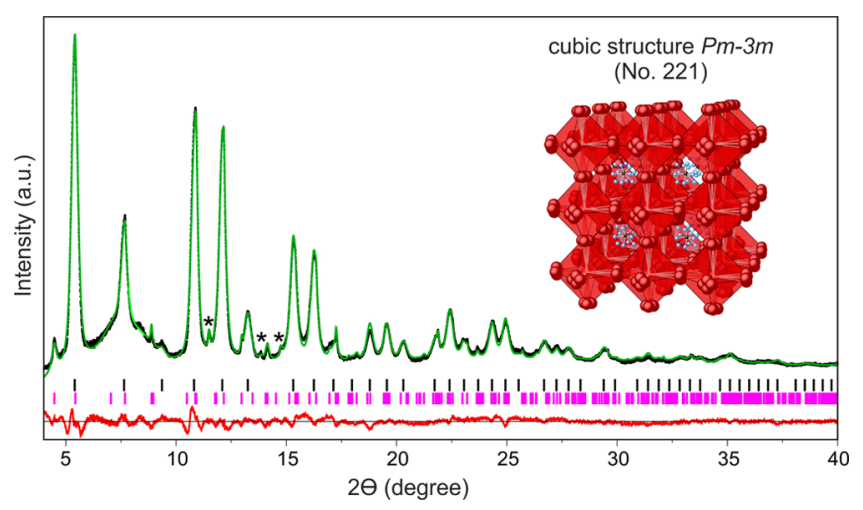

Figure 2. Synchrotron XRD pattern $(\lambda=0.565666 \AA)$ and its Rietveld fit for $\sim 12 \mathrm{~nm} \mathrm{FAPbBr} 3 \mathrm{NCs}$, containing an impurity of $\mathrm{NH}_{4} \mathrm{~Pb}_{2} \mathrm{Br}_{5}$ ( $\sim 6 \mathrm{wt} \%)$. Black, experimental data; green, calculated total trace that combines $\mathrm{Pm} \overline{3} \mathrm{~m}$ model of $\mathrm{FAPbBr}_{3}$ and the $14 / \mathrm{mcm}$ model of $\mathrm{NH}_{4} \mathrm{~Pb}_{2} \mathrm{Br}_{5} ;{ }^{10}$ red, difference plot; black and magenta vertical bars indicate Bragg peak locations for $\mathrm{FAPbBr}_{3}$ and $\mathrm{NH}_{4} \mathrm{~Pb}_{2} \mathrm{Br}_{5}$, respectively. Stars highlight minor peaks of an unknown contaminant. The inset illustrates the crystal structure of $\mathrm{FAPbBr}_{3}$ and disorder of Br-anions.

indicated the same primitive cubic structure (space group $P m \overline{3} m$, no. 221) reported for bulk crystals, with a small, but measurable, increase of the unit cell parameter with respect to bulk $(6.002$ vs $5.992 \AA) .{ }^{11}$ In $\mathrm{FAPbBr}_{3}$, the $\mathrm{PbBr}_{6}$ octahedra share their corners and the $\mathrm{Br}$ anions are disordered in four equivalent positions; consequently, the $\mathrm{Pb}-\mathrm{Br}-\mathrm{Pb}$ and cis- $\mathrm{Br}-$ $\mathrm{Pb}-\mathrm{Br}$ bond angles appear to deviate from their ideal values of $180^{\circ}$ and $90^{\circ}$, respectively, by up to $15^{\circ}$. As the slight reorientation of the $\mathrm{PbBr}_{6}$ octahedra is likely to occur as rigidbody rotations, of the 24 disordered $\mathrm{Br}$ ions surrounding a central $\mathrm{Pb}$ atoms, only 6 coherently define a regular octahedron, with cis- $\mathrm{Br}-\mathrm{Pb}-\mathrm{Br}$ angles of $90^{\circ}$. This finding implies a severe conditioning of the connectivity pattern of the neighboring octahedra, which cannot be considered cubic at the very local scale, but only on average. With the aim of explaining the chemical reason for such a deviation from linearity, it has been recently proposed that the tilting of the $\mathrm{PbBr}_{6}$ octahedra leads to a higher degree of space filling and, therefore, to a larger stability of the crystal structure. ${ }^{11}$ A careful analysis of the 

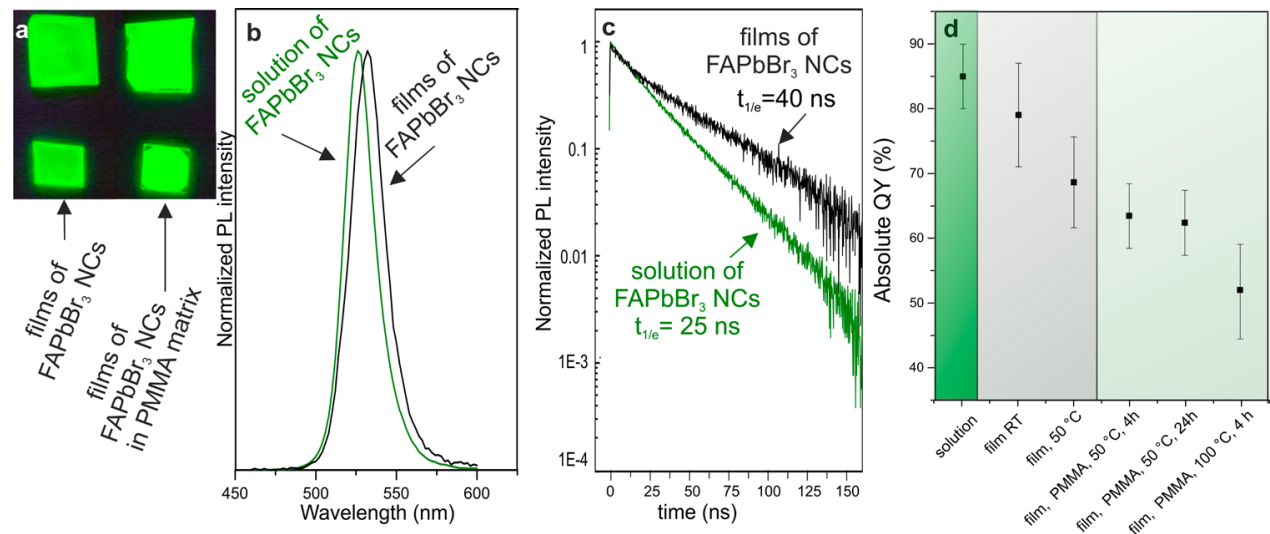

Figure 3. (a) Photograph of highly luminescent $\mathrm{FAPbBr}_{3} \mathrm{NC}$ films (bare and embedded in PMMA), under a UV lamp $(\lambda=365 \mathrm{~nm})$. (b) PL spectra of $\sim 12 \mathrm{~nm} \mathrm{FAPbBr} 3$ NCs in colloidal solution and in films. (c) Time-resolved (TR) PL traces for a solution and films of FAPbBr 3 NCs. (d) PL QYs of $\mathrm{FAPbBr}_{3} \mathrm{NCs}$ in various states: solution, bare films and polymer- (PMMA-) encapsulated films. All samples were prepared and tested in air.

synchrotron $\mathrm{XRD}$ pattern from the as-synthesized colloid detected a nanocrystalline impurity of $\mathrm{NH}_{4} \mathrm{~Pb}_{2} \mathrm{Br}_{5},{ }^{10}$ amounting typically to $5-10 \% . \mathrm{NH}_{4}{ }^{+}$could form by thermal decomposition of $\mathrm{FA}^{+}$during the synthesis of NCs. ${ }^{12}$

On the basis of our experience with $\mathrm{CsPbBr}_{3}$ and $\mathrm{MAPbBr}_{3}$ $\mathrm{NCs},{ }^{2,8 \mathrm{c}}$ the only alternatives within the $\mathrm{APbBr}_{3}$ family, we find $\mathrm{FAPbBr}_{3}$ to be much more robust in several regards. When an identical, repetitive precipitation/redispersion procedure (with acetonitrile/toluene) is applied to any of the $\mathrm{APbBr}_{3} \mathrm{NCs}$, only $\mathrm{FAPbBr}_{3}$ can retain bright $\mathrm{PL}$ after 2-3 cycles of purification. $\mathrm{CsPbBr}_{3} \mathrm{NCs}$ assume a nonluminescent state, whereas $\mathrm{MAPbBr}_{3} \mathrm{NCs}$ quickly decomposed. The PL properties and stability of purified $\mathrm{FAPbBr}_{3} \mathrm{NCs}$ were then investigated in films (Figure 3). A small, 5-10 nm shift in the PL peak is systematically seen upon preparation as films, compared to the solution spectra. The time-resolved (TR) PL traces from solutions of $12 \mathrm{~nm} \mathrm{NCs} \mathrm{(Figure} \mathrm{3c)} \mathrm{and} \mathrm{from} \mathrm{smaller} \mathrm{NCs} \mathrm{(8}$ $\mathrm{nm}$, Figure S7) are monoexponential with lifetimes of 25 and 7 ns, respectively. Such a size effect can be attributed to the higher exciton binding energy in such small crystallites due to quantum confinement. The QYs for both NC sizes were $>70 \%$. Contrary to conventional quantum dots, such as CdSe and InP NCs, perovskite NCs feature unusual, defect-tolerant photophysics, ${ }^{13}$ i.e., surface dangling bonds and intrinsic point defects such as vacancies do not form a high density of midgap states, known to trap carriers and thereby quench PL. CdSe and InP NCs, being defect-intolerant, require epitaxial passivation layers in order to exhibit bright PL. TR-PL traces from films of $12 \mathrm{~nm}$ $\mathrm{FAPbBr}_{3} \mathrm{NCs}$ show two characteristic lifetimes: one similar to the corresponding colloidal solution and a second, longer component ( $40 \mathrm{~ns}$ ) that can be attributed to increased exciton delocalization. The longer-living component has not been observed in the closely related $\mathrm{CsPbBr}_{3} \mathrm{NC}$ system. ${ }^{2} \mathrm{FAPbBr}_{3}$ NC films that were dried at room temperature exhibited QYs up to $81 \%$, whereas films dried at $50{ }^{\circ} \mathrm{C}$ for $24 \mathrm{~h}$ in air exhibited reduced QYs of $70 \%$. The ability of $\mathrm{FAPbBr}_{3} \mathrm{NCs}$ to retain bright $\mathrm{PL}$ also in the polymer-embedded form and under mild heating at $50-60{ }^{\circ} \mathrm{C}$ was then investigated. Such luminescent polymer films might eventually be used as backlight films in television displays.

NCs were mixed with poly(methyl methacrylate) (PMMA) in toluene, followed by drying at $50{ }^{\circ} \mathrm{C}$ for $4 \mathrm{~h}$ in air. These asprepared films exhibited QYs of $\sim 65 \%$, without noticeable deterioration after $24 \mathrm{~h}$. Higher temperature annealing (at 100
${ }^{\circ} \mathrm{C}, 4 \mathrm{~h}$ ) still resulted in high QYs of $\sim 50 \%$. Identical experiments with $\mathrm{CsPBr}_{3} \mathrm{NCs}$ led to QYs not exceeding $10 \%$ (Figure S8). Long-term-stability of $\mathrm{FAPbBr}_{3} \mathrm{NC}$ films requires additional investigations and further improvements are expected through various encapsulation strategies (core-shell morphologies, embedding into crystalline matrix, etc.).

High PL QYs and exciton delocalization may assist in achieving lasing from $\mathrm{FAPbBr}_{3} \mathrm{NC}$ emitters. ${ }^{5 \mathrm{a}}$ Figure 4

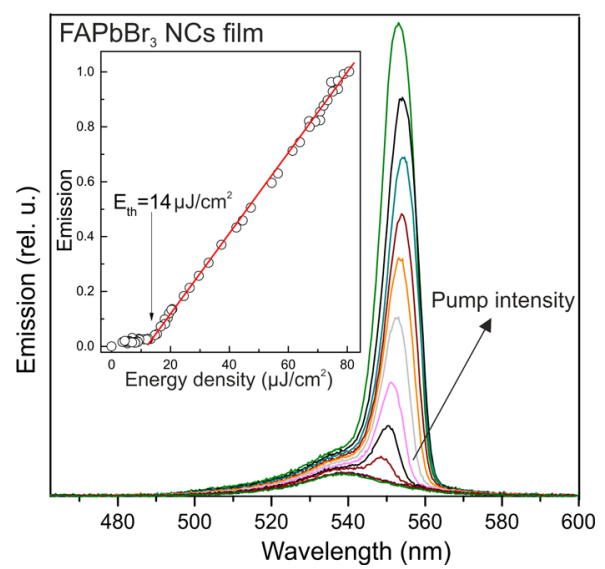

Figure 4. Amplified spontaneous emission (ASE) from a film of $\sim 12$ $\mathrm{nm} \mathrm{FAPbBr}{ }_{3} \mathrm{NCs}$. Inset: threshold behavior for the intensity of the ASE band.

presents amplified spontaneous emission (ASE) spectra of a film comprising $\sim 12 \mathrm{~nm} \mathrm{FAPbBr}$ NCs, obtained upon pulsed excitation $(400 \mathrm{~nm}, 100 \mathrm{fs})$. The initial PL peak with a fwhm of $26 \mathrm{~nm}$ is red-shifted by $14 \mathrm{~nm}$ and exhibits much narrower emission line widths ( $\mathrm{fwhm}=9 \mathrm{~nm}$ ), a clear signature of ASE. The redshift of the ASE band can be explained by the biexcitonic nature of the optical gain. ${ }^{14}$ The pump intensity threshold for ASE is $14 \pm 2 \mu \mathrm{J} \mathrm{cm}^{-2}$, one of the lowest among colloidal NCs emitting in the green range. ${ }^{5 \mathrm{a}, 14 \mathrm{a}, 15}$

In conclusion, we have presented a colloidal synthesis of highly uniform $\mathrm{FAPbBr}_{3}$ NCs. These NCs retain their bright emission with QYs of $50-80 \%$ in thin films and in a polymerembedded state, paving the way to a variety of applications such as blue-to-green down-converters or color enhancers in television displays, and in light-emitting diodes. 


\section{ASSOCIATED CONTENT}

\section{S Supporting Information}

The Supporting Information is available free of charge on the ACS Publications website at DOI: 10.1021/jacs.6b08900.

Experimental methods and supplementary figures (PDF)

\section{AUTHOR INFORMATION}

\section{Corresponding Author}

*mvkovalenko@ethz.ch

\section{Notes}

The authors declare no competing financial interest.

\section{ACKNOWLEDGMENTS}

This work was financially supported by the European Union through the FP7 (ERC Starting Grant NANOSOLID, GA No. 306733) and by the Swiss Federal Commission for Technology and Innovation (CTI-No. 18614.1 PFNM-NM). The authors thank Dr. Stefan Günther for assistance with femtosecond laser sources, Dr. A. Cervellino and the technical staff at the MSX04SA beamline of the Swiss Light Source for the support during X-ray data collection and Dr. Nicholas Stadie for reading the paper.

\section{REFERENCES}

(1) http://www.nrel.gov/ncpv/images/efficiency_chart.jpg.

(2) Protesescu, L.; Yakunin, S.; Bodnarchuk, M. I.; Krieg, F.; Caputo, R.; Hendon, C. H.; Yang, R. X.; Walsh, A.; Kovalenko, M. V. Nano Lett. 2015, 15, 3692-3696.

(3) (a) Nedelcu, G.; Protesescu, L.; Yakunin, S.; Bodnarchuk, M. I.; Grotevent, M. J.; Kovalenko, M. V. Nano Lett. 2015, 15, 5635-5640. (b) Akkerman, Q. A.; D’Innocenzo, V.; Accornero, S.; Scarpellini, A.; Petrozza, A.; Prato, M.; Manna, L. J. Am. Chem. Soc. 2015, 137, 10276-10281. (c) Zhang, D.; Yang, Y.; Bekenstein, Y.; Yu, Y.; Gibson, N. A.; Wong, A. B.; Eaton, S. W.; Kornienko, N.; Kong, Q.; Lai, M.; Alivisatos, A. P.; Leone, S. R.; Yang, P. J. Am. Chem. Soc. 2016, 138, 7236-7239. (d) Bekenstein, Y.; Koscher, B. A.; Eaton, S. W.; Yang, P.; Alivisatos, A. P. J. Am. Chem. Soc. 2015, 137, 16008-16011. (e) Akkerman, Q. A.; Motti, S. G.; Srimath Kandada, A. R.; Mosconi, E.; D’Innocenzo, V.; Bertoni, G.; Marras, S.; Kamino, B. A.; Miranda, L.; De Angelis, F.; Petrozza, A.; Prato, M.; Manna, L. J. Am. Chem. Soc. 2016, 138, 1010-1016. (f) Shamsi, J.; Dang, Z.; Bianchini, P.; Canale, C.; Stasio, F. D.; Brescia, R.; Prato, M.; Manna, L. J. Am. Chem. Soc. 2016, 138, 7240-7243. (g) Lignos, I.; Stavrakis, S.; Nedelcu, G.; Protesescu, L.; deMello, A. J.; Kovalenko, M. V. Nano Lett. 2016, 16, 1869-1877.

(4) (a) De Roo, J.; Ibáñez, M.; Geiregat, P.; Nedelcu, G.; Walravens, W.; Maes, J.; Martins, J. C.; Van Driessche, I.; Kovalenko, M. V.; Hens, Z. ACS Nano 2016, 10, 2071-2081. (b) Pan, J.; Quan, L. N.; Zhao, Y.; Peng, W.; Murali, B.; Sarmah, S. P.; Yuan, M.; Sinatra, L.; Alyami, N. M.; Liu, J.; Yassitepe, E.; Yang, Z.; Voznyy, O.; Comin, R.; Hedhili, M. N.; Mohammed, O. F.; Lu, Z. H.; Kim, D. H.; Sargent, E. H.; Bakr, O. M. Adv. Mater. 2016, 28, 8718.

(5) (a) Yakunin, S.; Protesescu, L.; Krieg, F.; Bodnarchuk, M. I.; Nedelcu, G.; Humer, M.; De Luca, G.; Fiebig, M.; Heiss, W.; Kovalenko, M. V. Nat. Commun. 2015, 6, 8056. (b) Wang, Y.; Li, X.; Song, J. D.; Xiao, L.; Zeng, H.; Sun, H. Adv. Mater. 2015, 27, 71017108. (c) Pan, J.; Sarmah, S. P.; Murali, B.; Dursun, I.; Peng, W.; Parida, M. R.; Liu, J.; Sinatra, L.; Alyami, N.; Zhao, C.; Alarousu, E.; Ng, T. K.; Ooi, B. S.; Bakr, O. M.; Mohammed, O. F. J. Phys. Chem. Lett. 2015, 6, 5027-5033.

(6) (a) Li, X.; Wu, Y.; Zhang, S.; Cai, B.; Gu, Y.; Song, J.; Zeng, H. Adv. Funct. Mater. 2016, 26, 2435-2445. (b) Li, G.; Rivarola, F. W. R.; Davis, N. J. L. K.; Bai, S.; Jellicoe, T. C.; de la Peña, F.; Hou, S.; Ducati, C.; Gao, F.; Friend, R. H.; Greenham, N. C.; Tan, Z.-K. Adv. Mater. 2016, 28, 3528-3534.
(7) Stoumpos, C. C.; Malliakas, C. D.; Peters, J. A.; Liu, Z.; Sebastian, M.; Im, J.; Chasapis, T. C.; Wibowo, A. C.; Chung, D. Y.; Freeman, A. J.; Wessels, B. W.; Kanatzidis, M. G. Cryst. Growth Des. 2013, 13, $2722-2727$.

(8) (a) Tyagi, P.; Arveson, S. M.; Tisdale, W. A. J. Phys. Chem. Lett. 2015, 6, 1911-1916. (b) Hassan, Y.; Song, Y.; Pensack, R. D.; Abdelrahman, A. I.; Kobayashi, Y.; Winnik, M. A.; Scholes, G. D. Adv. Mater. 2016, 28, 566-573. (c) Vybornyi, O.; Yakunin, S.; Kovalenko, M. V. Nanoscale 2016, 8, 6278-6283. (d) Huang, S.; Li, Z.; Kong, L.; Zhu, N.; Shan, A.; Li, L. J. Am. Chem. Soc. 2016, 138, 5749-5752.

(9) (a) Rehman, W.; Milot, R. L.; Eperon, G. E.; Wehrenfennig, C.; Boland, J. L.; Snaith, H. J.; Johnston, M. B.; Herz, L. M. Adv. Mater. 2015, 27, 7938-7944. (b) Zhumekenov, A. A.; Saidaminov, M. I.; Haque, M. A.; Alarousu, E.; Sarmah, S. P.; Murali, B.; Dursun, I.; Miao, X.-H.; Abdelhady, A. L.; Wu, T.; Mohammed, O. F.; Bakr, O. M. ACS Energy Lett. 2016, 1, 32-37.

(10) Powell, H. M.; Tasker, H. S. J. Chem. Soc. 1937, 119-123.

(11) Hanusch, F. C.; Wiesenmayer, E.; Mankel, E.; Binek, A.; Angloher, P.; Fraunhofer, C.; Giesbrecht, N.; Feckl, J. M.; Jaegermann, W.; Johrendt, D.; Bein, T.; Docampo, P. J. Phys. Chem. Lett. 2014, 5, 2791-2795.

(12) Shriner, R. L.; Neumann, F. W. Chem. Rev. 1944, 35, 351-425. (13) (a) Zakutayev, A.; Caskey, C. M.; Fioretti, A. N.; Ginley, D. S.; Vidal, J.; Stevanovic, V.; Tea, E.; Lany, S. J. Phys. Chem. Lett. 2014, 5, 1117-1125. (b) Brandt, R. E.; Stevanović, V.; Ginley, D. S.; Buonassisi, T. MRS Commun. 2015, 5, 265-275.

(14) (a) Grim, J. Q.; Christodoulou, S.; Di Stasio, F.; Krahne, R.; Cingolani, R.; Manna, L.; Moreels, I. Nat. Nanotechnol. 2014, 9, 891895. (b) Klimov, V. I.; Mikhailovsky, A. A.; Xu, S.; Malko, A.; Hollingsworth, J. A.; Leatherdale, C. A.; Eisler, H.-J.; Bawendi, M. G. Science 2000, 290, 314-317.

(15) (a) She, C.; Fedin, I.; Dolzhnikov, D. S.; Dahlberg, P. D.; Engel, G. S.; Schaller, R. D.; Talapin, D. V. ACS Nano 2015, 9, 9475-9485. (b) Wang, Y.; Yang, S.; Yang, H.; Sun, H. Adv. Opt. Mater. 2015, 3, 652-657. (c) Wang, Y.; Leck, K. S.; Ta, V. D.; Chen, R.; Nalla, V.; Gao, Y.; He, T.; Demir, H. V.; Sun, H. Adv. Mater. 2015, 27, 169-175. 